\title{
The Comprehensive Competitiveness of Tesla Based on Financial Analysis: A Case Study
}

\author{
Yujie Qin ${ }^{1, *}$, , Yuqing $\mathrm{Xiao}^{2, \dagger}$, and Jiawei Yuan ${ }^{3, \dagger}$ \\ ${ }^{1}$ School of Economics, Nankai University. China 300071, No.94 Weijin Road, Nankai District, Tianjin, P.R. China \\ ${ }^{2}$ School of Business, Hunan Agricultural University. China 410128, East lake street, Furong District, Changsha City, \\ Hunan Province, China. \\ ${ }^{3}$ School of Business, Central South University of Forestry and Technolog. China 410004, No. 498 South Shaoshan \\ Road, Changsha City, Hunan Province, China. \\ * Corresponding author:1812145@mail.nankai.edu.cn. \\ These authors contributed equally.
}

\begin{abstract}
Contemporarily, the new energy automobile industry has developed rapidly, which has attracted plenty of investors due to the great market potential. The increasing listed companies lead to fierce competition in this industry, i.e., it is crucial to analyse the comprehensive competitiveness of these companies for both industry and investors. Based on relative literatures, Tesla, a leader in the industry, is selected as a case to analyse. Specifically, we used Tesla's financial statements from 2018 to 2020 and compared the financial performance with other competitors in the industry. Through the case study method, the current issues of Tesla is pointed out, which have a negative impact on financial performance. Subsequently, some feasible suggestions are put forward accordingly. These results serve as a strong basis for the long-term investment value of listed companies and help investors make correct investment decisions.
\end{abstract}

Keywords: Tesla, Financial Analysis.

\section{INTRODUCTION}

Nowadays, the global warming and air pollution are increasingly severe, which attracts more attention to the topic about reducing auto emissions since 1990s for the whole world. Therefore, energy saving and environmental protection have gradually become a rigid requirement for the development of the automotive industry. On this occasion, the electric vehicles industry has developed quickly in the modern days. This study will focus on the comprehensive competitiveness analysis of the public companies in the electric vehicles industry for several reasons. Firstly, the economic value as well as impacts of a listed company are constantly improving with the vigorous development of the whole industry. In addition, the competitiveness analysis of the listed companies will find out the encountered problems in the development. In this case, it will better promote the development of the whole industry and achieve the ultimate goal of energy saving and emission reduction and environmental protection.
As a matter of fact, there are plenty of relevant literatures on this topic. Xiujuan Luo made some suggestions to the listed auto companies in China through the competitiveness analysis in order to better develop the national electric vehicle industry and economy [1]. Yue $\mathrm{Xu}$ found that analysing the competitiveness of the electric vehicle industry helped to determine the current development stage of the industry in China [2]. However, most studies focus on analysing the competitiveness of the whole environment of electric vehicle industry, while few of them use a specific company or case to analysis the competitiveness.

In order to fill the gap in this research field, we used case analysis to analyse the comprehensive competitiveness of the new energy automobile market. The Tesla is selected as the objective, which is one of the biggest automotive and energy company in the world. First, we analysed the current condition of the industry to determine the main competitors and research priorities of Tesla. Then we calculated Tesla's financial indicators in recent year and analysed its main 
competitiveness based on these financial indicators. Finally, the main existing problems are discussed and corresponding strategies are proposed to improve the state of operation. It is expected to discover the comprehensive competitiveness of listed companies in the new energy automobile industry based on the financial research of Tesla. Besides, our results provide some valuable references for the long-term investment value of listed companies in this industry. The rest of the paper is organized as follow: the method of this study is introduced in Sec. 2; then, the performance analysis and current issues of Tesla are presented in Sec. 3 and 4, respectively; subsequently, the discussions are demonstrated in Sec. 5; a brief summary is given in Sec. 6 eventually.

\section{METHOD}

Three research methods are utilized to carry out our research, including literature review method, comparative study method and case study method. Among them, literature review method and comparative study method are commonly used in previous academic studies. The innovation of this research is the application of the case study method, which focuses on a typical company in the new energy automobile industry (the Tesla). It is different from the previous studies which makes general analysis of all companies in the industry as a whole. Based on the analysis of the specific financial indicators of Tesla, one has a clearer understanding of the competitiveness of new energy vehicle listed companies.

\section{1. literature review method}

The literature review method consists of collecting, identifying, and collating literature, and forming a scientific understanding of facts through the study of the literature. They can serve as a basis for knowledge development, create guidelines for policy and practice, provide evidence of an effect, and have the capacity to engender new ideas and directions for a particular field if well conducted [3]. We first read some literatures on authoritative business journals about the comprehensive competitiveness of the new energy vehicle, e.g., International Journal of Business Research and Information Technology, Frontiers in Economics and Management Research, Forbes Magazine. Subsequently, a literature review is conducted systematically, which helps to find the gap in the comprehensive competitiveness research of current listed companies and determine our research question. Then, we refer to some books on finance to find calculation methods for financial indicators suitable for comprehensive competitiveness analysis. Besides, authoritative new energy vehicle industry reports in recent years are searched to collect information of the current condition and main competitors of Tesla in the new energy automobile market. In general, we try our best to obtain true and reliable information as well as professional knowledge through this method.

\subsection{Case studies method}

Generally, case studies are based on an in-depth investigation of a single individual to explore the reason behind complex phenomena [4]. For the evaluation of financial performance, the financial data is collected from annual report of Tesla to calculate financial ratios, which can identify the key problem currently with following steps. Firstly, some of the calculated ratios are applied to measure the profitability in Tesla, including gross profit margin, operating profit margin, asset turnover, profit margin for return on common equity, capital structure leverage and ROCE. Additionally, in order to assess the short-term and longterm solvency, we employ other calculated ratios (e.g., current ratio, quick ratio, long-term debt to long-term capital and long-term debt to total equity). Moreover, we use calculated ratios payable turnover, inventory turnover, receivable turnover to analyse the firm's working capital management. Finally, revenue growth rate and sales to net working capital are used for evaluating net assets growth rate to assess the growth rate.

\subsection{Comparative study method}

Comparative study is carried out to quantify relationships two or more variables by observing different result with different treatment [5]. In this paper, vertical comparison is utilized by adopting 2018 2020 financial data from annual report to find out what indicators drive the change in Tesla. Besides. horizontal comparison is also applied by presenting strong competitors' financial ratio to evaluate the financial performance in Tesla.

\section{TESLA'S FINANCIAL PERFORMANCE ANALYSIS}

\subsection{Profitability Analysis}

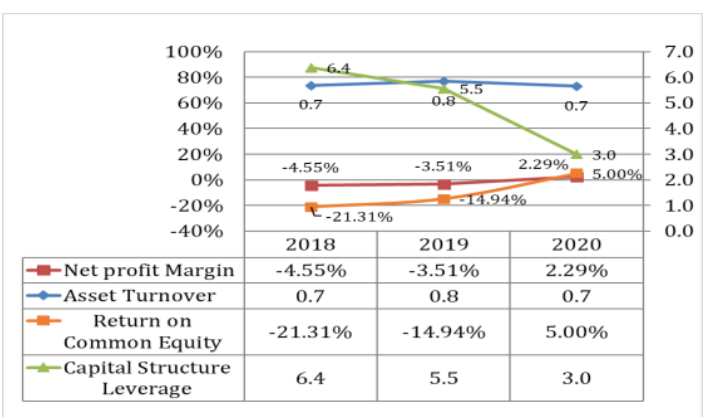

Fig. 1. Return on common equity and its breakdown, including net profit margin, asset turnover, and capital structure leverage. 
As shown in Fig. 1, the ROCE increased from $21.31 \%$ in 2018 to $-14.94 \%$ in 2019 mainly due to the increment of 137,969 Model 3 cash deliveries driving the growth rate $14.2 \%$ in asset turnover. From year 2019 to 2020 , the ROCE turns from negative to positive, which means that Tesla has finally made the profit from its performance. This can be attributed to the improved net profit margin from $-3.51 \%$ to $2.29 \%$ in the 2020, which covers the negative impact by decreased asset turnover influenced by COVID-19. Besides, it compensates larger financing part by equity mainly due to the $114 \%$ growth rate in additional paid in capital to $\$ 27,261$ million. As we can see from Fig. 2 , the net profit margin turns from negative from positive based on the better management in cost of sales, especially in the operating expense as well as the increase of 129,268 Model 3 and Model Y cash deliveries.

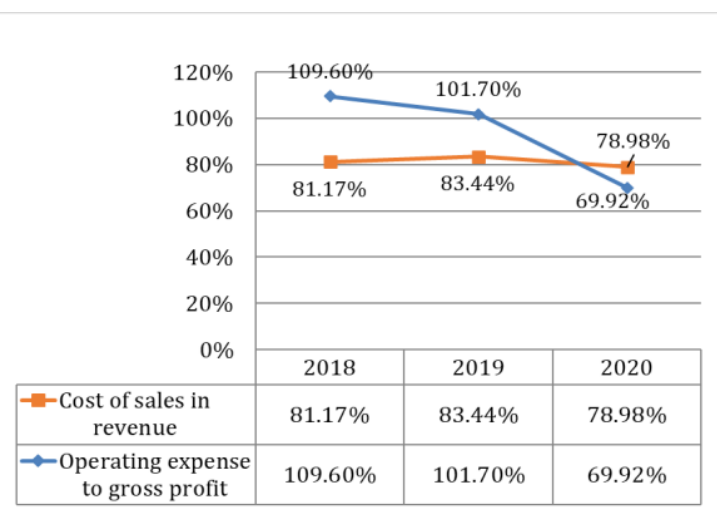

Fig. 2. Cost of sales and operating expense in revenue

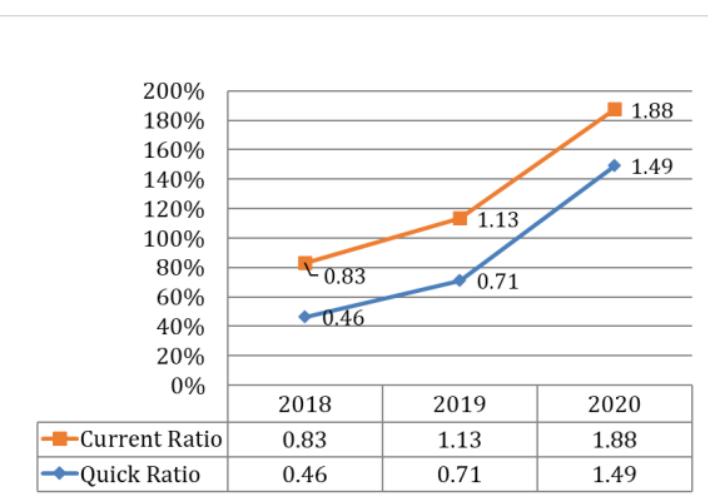

Fig. 3. Short-term solvency : the current and quick ratio

\subsection{Solvency analysis}

Current ratio and quick ratio are all increased from the year 2018 to 2020 owing to the highly liquid investments with an original maturity of three months or less at the date of purchase invested in the 2019 (seen from Fig. 3). Therefore, the cash and cash equivalents of Tesla increased about 19\% from the year 2019 to
2020. The increased of cash is the biggest contributor to the current assets increase, i.e., promotes the huge increase of the current ratio and quick ratio. The increase of the current ratio means the increasing ability of debt paying.

The increase in two long-term solvency ratios shows the financing preference turns to equity. This situation is mainly contributed by the slide in Long-term debt and finance leases from \$1232 million in 2019 to $\$ 1094$ million in 2020. In addition, growth paid in capital from $\$ 12737$ million in 2019 to $\$ 27,261$ million in 2020 is also the causality of this situation.

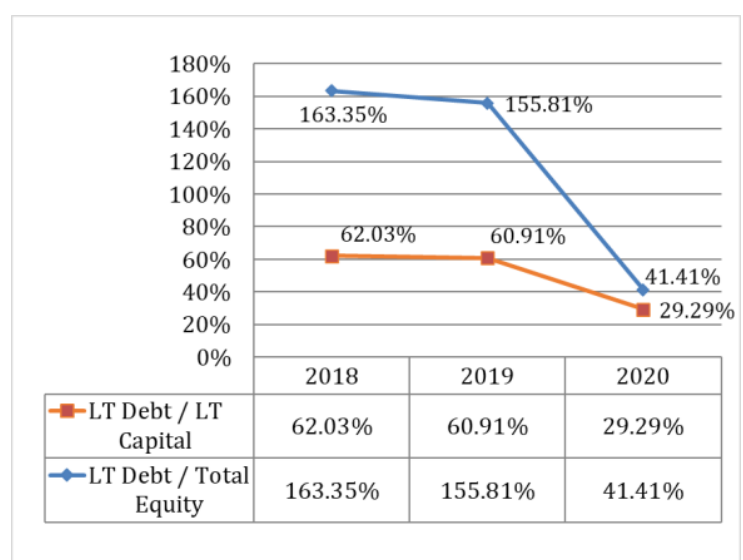

Fig. 4. Long-term solvency: long term debt to long term capital and long-term debt to total equity

\subsection{Operational capacity analysis}

\begin{tabular}{|c|c|c|c|}
\hline \multirow{6}{*}{$\begin{array}{r}35 \\
30 \\
25 \\
20 \\
15 \\
10 \\
5 \\
0\end{array}$} & \multicolumn{3}{|c|}{29.3} \\
\hline & \multicolumn{3}{|c|}{21.6} \\
\hline & \multicolumn{3}{|c|}{ 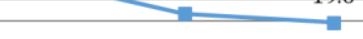 } \\
\hline & 6.3 & 5.8 & 5.2 \\
\hline & 6.5 & 6.2 & 6.5 \\
\hline & 2018 & 2019 & 2020 \\
\hline $\begin{array}{c}\text { Accounts } \\
\text { Receivable } \\
\text { turnover }\end{array}$ & 29.3 & 21.6 & 19.6 \\
\hline $\begin{array}{r}- \text { Inventory } \\
\text { Turnover }\end{array}$ & 6.5 & 6.2 & 6.5 \\
\hline $\begin{array}{c}\text {-Acoounts payable } \\
\text { turnover }\end{array}$ & 6.3 & 5.8 & 5.2 \\
\hline
\end{tabular}

Fig. 5. Accounts receivable turnover, inventory turnover and accounts payable turnover.

\subsubsection{Accounts receivable turnover}

From the year 2018 to 2019, the receivables of the Tesla are decreasing to 19.6 (depicted in Fig. 5), which shows the worse performance of receivables management. Tesla has been influenced by the COVID19 , customer may not be able to pay a great amount at a time. 


\subsubsection{Inventory turnover}

Inventory turnover is stable in the three years, but Tesla's inventory turnover is far worse than traditional fuel car companies e.g., Toyota Motor [12] and Ford Motor [13]. The reasons for Tesla's low inventory turnover are discussed as follow.

Firstly, compared with the traditional fuel vehicle brand, Tesla cannot compete with it in terms of technology and market demand, and the main sales vehicles cannot achieve mass production. Tesla has three models, while Ford has more than 30 models to share the cost of inventory. Thus, Tesla cannot guarantee a high inventory turnover rate as a traditional car company. Secondly, the relationship between labour and capital is tense. $2 \%$ to $3 \%$ of the total number of employees are fired because they fail to achieve their work performance, and workers are forced to work. Issues such as manual manufacturing of major auto parts have occurred. The relationship between the company members and leaders, members and the company will directly affect the production process of the company. If it causes contradictions among workers, it will lead to the risk of production chain interruption.

\subsubsection{Accounts payable turnover}

Accounts payable turnover is continuing decreasing. Under the impact of COVID-19 pandemic in 2020, Tesla may not be able to repay the payable in time. Therefore, the Accounts payable turnover is decreasing. The decreasing of Accounts payable turnover indicates the well management of the payable of Tesla.

\subsection{Growth ability}

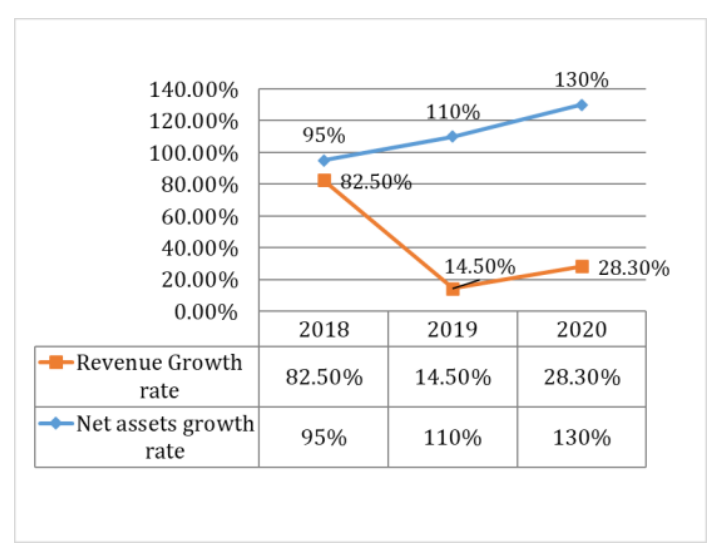

Fig. 6. Revenue growth rate and net assets growth rate

\subsubsection{Revenue growth}

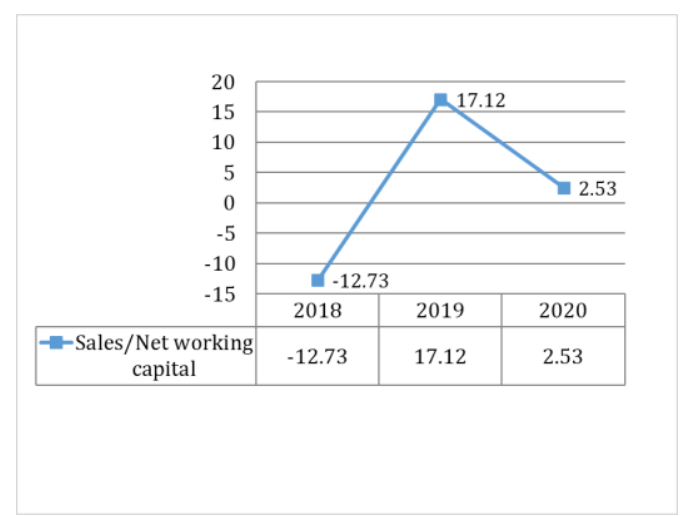

Fig. 7. Sales/Net working capital

From the year 2018 to 2019, revenue growth rate is fluctuating as exhibited in Fig. 6. Revenue growth rate is decreasing from $82.5 \%$ in 2018 to $14.5 \%$ in 2019 . Affected by factors such as the decline of China's new energy vehicle subsidy policy, China's new energy vehicle production and sales have declined year-on-year since the second half of 2019. As a consequence, the revenue growth rate is decreasing. Although affected by the COVID-19 in 2020, Tesla's growth rate is still in increasing, indicating that the large customer demand for the electric car.

\subsubsection{Net assets growth rate}

As shown in Fig.7, growth of total assets is increasing from the year 2018 to 2020 , meaning that Tesla has expand fast in the asset management scale in the three years. However, from the year 2019 to 2020, the sales to net working capital ratio is decreasing from 17.12 to -2.53 , i.e., Tesla may have the over capitalisation risk.

\subsection{Comparative analysis of financial performance between Tesla and other companies in the same industry}

\subsubsection{Profitability Analysis}

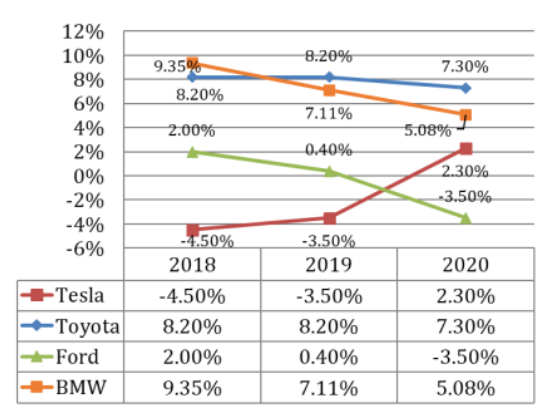

Fig. 8. The comparison of net profit margin for different companies 
Compared to other companies in the same industry (given in Fig. 8), Tesla is unprofitable until 2020. Besides, the profitability is lower than the other companies. Tesla is still in an early stage of development since electric vehicles producing is an emerging industry, i.e., the profit margin is still low compared to other companies.

\subsubsection{Liquidity analysis}

In the 2018, Tesla had a low current ratio compared to other companies, denoting the company may have problems paying its current liabilities. However, from 2018 to 2019, Tesla's current ratio has exceeded other companies, which means that Tesla's ability to pay for debt is increasing and great than others.

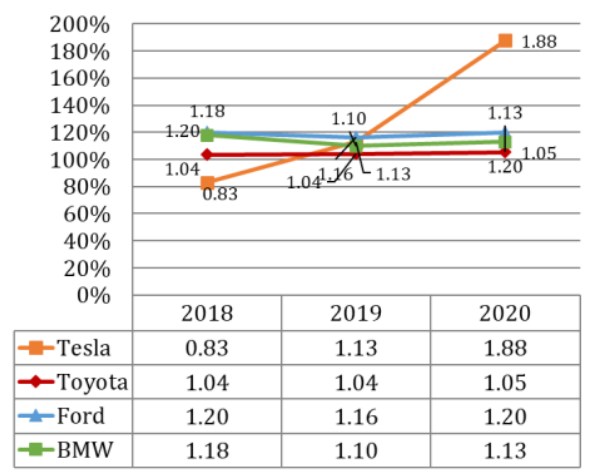

Fig. 9. Current ratio for Tesla, Toyota, Ford \&BMW

\subsubsection{Operational capacity analysis}

\begin{tabular}{|c|c|c|c|}
\hline & \multicolumn{3}{|l|}{29.3} \\
\hline \multirow{2}{*}{$\begin{array}{l}30 \\
25\end{array}$} & \multicolumn{3}{|l|}{ L } \\
\hline & \multicolumn{2}{|r|}{21.6} & 19.6 \\
\hline \multirow{3}{*}{$\begin{array}{l}20 \\
15 \\
10\end{array}$} & 14.3 & 10.10 & 12.7 \\
\hline & \multicolumn{2}{|l|}{7} & 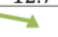 \\
\hline & 3.2 & 3.2 & 3.2 \\
\hline \multirow{2}{*}{$\begin{array}{l}5 \\
0\end{array}$} & \multicolumn{2}{|l|}{$\bullet$} & $\rightarrow$ \\
\hline & 2018 & 2019 & 2020 \\
\hline -a-Tesla & 29.3 & 21.6 & 19.6 \\
\hline - -Toyota & 3.2 & 3.2 & 3.2 \\
\hline$\triangle$ Ford & 14.3 & 16.9 & 12.7 \\
\hline
\end{tabular}

Fig. 10. Accounts Receivable turnover comparison for Tesla, Toyota \& Ford.

As demonstrated in Fig. 10, Tesla's account receivables turnover is much higher than other companies. As the benefit of long-term savings on fuel costs and the increased environmental awareness, it encourages more buyers to switch from a conventional car to an electric car. Therefore, the barging power of Tesla is very high, i.e., Tesla's account receivables turnover is much higher.

\subsubsection{Growth ability}

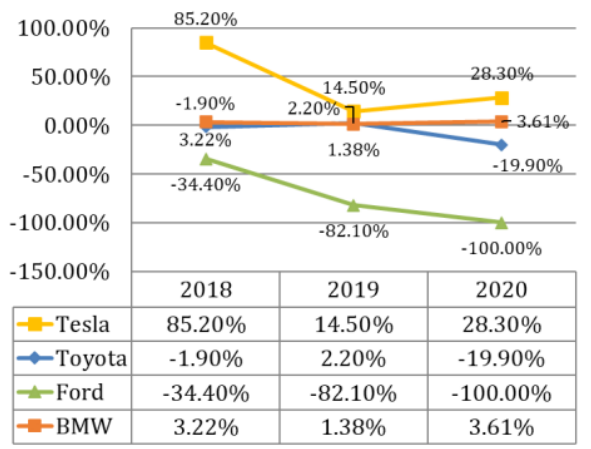

Fig. 11. Revenue growth comparison for Tesla, Toyota, Ford \&BMW.

As presented in Fig. 11, the revenue growth rate of Tesla is greater than the other companies, which shows a great development ability in the future. Unlike other company in the auto industry, the products of Tesla are more attractive to the customs. Under the promotion of the government, people may get the awareness of environmental protection and energy saving. In this case, more people like to buy the electric cars other than the traditional vehicles. Thereby, the growth ability of Tesla is greater than other companies that only sales traditional vehicles.

\section{PROBLEM IN TESLA'S FINANCIAL PERFORMANCE}

Through financial statement analysis and comparison with similar companies inl automobile industry, we find three existing problems with Tesla's financial performance: low profitability, decreasing inventory turnover rate, and the sharply decrease of the sales to net working capital.

\subsection{Problems with profitability}

We analyse Tesla's financial statements for the past five years and find that though its profitability has improved, its profit margin, ROCE and other profitability indicators are still lower than other competitors. Through further analysis of its financial statements, we find that its operating costs are increasing in recent year which are at a relatively high level in the industry. The reason is that Tesla are highly dependent on their suppliers, which are most single source suppliers for necessary components of their products. This is mentioned in their financial statement disclosure. 


\subsection{Problems with inventory turnover rate}

Based on preliminary comparison of financial indicators and find that, Tesla's inventory turnover rate has increased in 2020, which increased from 6.2 to 6.5. This reminds us that Tesla may have some issues in inventory management or logistics system. By analysing its financial statements, one finds that employee frequent turnover may be the reason for the decline in its inventory turnover rate.

\subsection{Problems with the sales to net working capital}

The sales to net working capital decreased sharply from 17.12 in 2019 to 2.53 in 2020, which presented the overcapitalisation in Tesla. Besides, it also can be demonstrated by the increase in current ratio from 1.13 in 2019 to 1.88 in 2020 and quick ratio from 0.71 in 2019 to 1.49 in 2020.This situation means the surplus of capital and overcapacity. After the overcapacity reaches a certain level, there will be confusion, stagnation and crisis in production. Therefore, the overcapitalization will not only have a big impact on the company's operations in the short term, but also damage the company's financial goals in the long run.

\section{DISCUSSION}

In this section, further analysis is demonstrated to Tesla's financial performance with some feasible suggestions to improve its financial performance based on the current internal or external environment. These suggestions may help Tesla further improve its comprehensive competitiveness.

\subsection{Measures to Improve profitability}

In order to improve Tesla's profitability, we believe that Tesla needs to pay more attention to their cost control. As Alghalith N. mentioned in Ref. [6], if Tesla cannot find a way to reduce its cost, its price cannot be further reduced, which will affect its sales and further affect its long-term profitability. Through the in-depth analysis of the Five Forces Analysis, we found that Tesla's suppliers have higher bargaining power, which may be the cause of their perennial high costs [7]. Take its core component battery as an example. Tesla's main supplier is a Japanese company called Panasonic. It provides Tesla Motors with support so that Tesla can maintain it position at the technological forefront [8]. Panasonic, the sole battery supplier of Tesla, have overexcessive bargaining power, which give him enough power to set a higher price. Tow measures are provided in order to help Tesla successfully reduce the cost of its raw materials.

\subsubsection{Find alternative suppliers}

In order to tackle this problem, Tesla needs to find more alternative suppliers to reduce the bargaining power of its suppliers. The best way to realize it is to find more local supplier in who can provide a lower price and save the cost of delivery. It is worth mentioning that Tesla has low dependency on its suppliers as they work as original equipment manufacturer in China. Therefore, it may be a good choice to enlarge Chinese market and establish more factories. Tesla can set up a new supply chain in China that select more local manufacturer to produce components for them [9].

\subsubsection{Improve its technology}

Tesla also needs to further improve its technological innovation capabilities and masters the production technology of its core components (e.g., battery), which can effectively reduce the reliance on their suppliers like Panasonic. In the future, maybe Tesla can establish its own factory to partially provide batter cars for itself.

\subsection{Measures to improve inventory turnover rate}

Tesla stated in its 2020 annual report that none of their key employees is bound by an employment agreement for any specific term and they may not be able to successfully attract and retain senior leadership. The frequent turnover of senior manager who is responsible for inventory might be a cause of the high inventory turnover rate. Recruiting efforts, particularly for senior employees, may be time-consuming. In addition, new senior managers are not very familiar with the company's business, internal environment, culture, and interpersonal relationships, which may have a negative effect on the efficiency of the company [10]. In order to solve this problem, Tesla needs to take some measures to retain the core employees of the company.

\subsubsection{Increasing employee salaries}

Tesla disclosed in its financial report due to COVID-19, which fired many temporary workers and lowered the basic wages of their employee in April 2020. The reduction in employee wages may trigger their dissatisfaction and result in their resigning from Tesla. The company may also consider emphasis on equity-based award and benefits for employees, closely align the interests of employees with long-term development of the company as well as reduce the probability of employees' frequent job-hopping [11]. 


\subsubsection{Provide more jobs}

Tesla needs to stop layoffs in order to reduce the negative publicity related to its employee recruitment. They may be impacted by perceptions relating to reductions in force that they have conducted in the past and the departure of certain senior personnel for various reasons. A way to erase the negative impression is to provide more jobs, which conveyed positive signals to the labour market and the employees of its own company.

\subsection{Measures to improve the sales to net working capital}

The main reason for the sharp decline in this indicator is the dramatic growth of Tesla's capital. In recent years, Tesla's stock price has continued growing. Some scholars have said that Tesla's value may be overvalued [12]. Tesla's overcapitalisation has brought enough funds to the company to expand its business, but it may bring higher risks to Tesla. Tesla should reduce its capital from both long-term debt and shares.

\subsubsection{Reduce long-term debt}

Tesla can consider repay some long-term debts to reduce its capital. Since Tesla has make a profit in 2020 , it can develop a scheme of capital reduction and consider decrease the burden of debt by earlier debt payment. Debt restructuring with banks and other lenders to reduce the interest obligation may be another way to deal with its overcapitalisation.

\subsubsection{Reduce shares}

Tesla needs to moderately reduce investor expectations to ensure that its stock price can no longer rise sharply, so as to maintain the company's stability and reduce financial risks. If possible, Tesla can consider repurchasing some shares appropriately. All official expenses should be minimized and a conservative dividend declaration should be planned.

\section{CONCLUSION}

\subsection{Summary main findings}

In conclusion, the enhanced profitability, strong solvency and growth ability of Tesla have been discovered. In order to support the statements, the evaluations are presented based on profitability, solvency, operating management and growth ability by financial ratios from 2018 to 2020 in Tesla as well as the comparison with its main competitor. Besides, it is find that the operating management needed to be improved especially in three aspects: strong bargaining power of suppliers, high employee turnover and overcapitalisation. Subsequently, suggestions are proposed accordingly to figure out those problems. Specifically, the company can find alternative suppliers and improve its technology to enhance their vertical integration for the first problem. As for the second problem, they can improve their employees' salaries, equity-based award and other benefit to stop layoffs and provide more jobs to erase the negative impression. With regard to the third issue, Tesla can repay some long-term debts, restructure debts and repurchase some shares to control overcapitalisation.

\subsection{Limitations and prospect}

However, there are some limitations existing in the study. Firstly, it only compares three years financial result in the financial analysis, which may be not accurate and sufficient. The intrinsic is analysing three years financial result may not be able to see the trends of the company performance. In the future study, it is better to analysing more years of the company as measuring the financial performance of the company. Secondly, the study only selects other four companies in the industry in order to assess the performance of Tesla by comparison. There is a risk that the four companies cannot represent the whole industry appropriately. Therefore, it is necessary to choose more companies in the same industry for comparison in the future. Thirdly, the study is focus on the competitiveness analysis of public companies in the electric vehicles industry as an example of Tesla. Tesla's whole financing statements are chosen to measure its competitiveness in the study. However, it has the energy storage business except for selling electric vehicle, i.e., it is not accurate enough to assess its performance in the electric vehicles industry via whole business. Therefore, it is more appropriate to separate the results of financial statements in order to get more precisely analysing of electric vehicles industry in the future.

\section{REFERENCES}

[1] Xiujuan Luo, Competitiveness analysis and evaluation of China's auto industry listed corporation, Chongqing University (2014)

[2] Yue Xu, Research on the Competitiveness of New Energy Vehicle Listed Companies, China Economic and Trade Guide (2020)

[3] Snyder H. Literature review as a research methodology: An overview and guidelines. Journal of Business Research 104 (2019)

[4] Heale R, Twycross A. What is a case study? Evidence-Based Nursing 21 (2018)

[5] Bukhari, Syed Aftab Hassan. What is Comparative Study. Available at SSRN 1962328 (2011) 
[6] Alghalith N. Tesla: innovation with information technology. International Journal of Business Research and Information Technology 5(1) (2018)

[7] Jing X U. Analysis of the Operation Strategy of Tesla Inc. in China. Frontiers in Economics and Management Research 1(1) (2020)

[8] Rogowsky, Mark. Numbers Don't Lie: Tesla Is Beginning To Put The Hurt On The Competition.Forbes. Forbes Magazine 24 (2013)

[9] Crook T R, Combs J G. Sources and consequences of bargaining power in supply chains. Journal of operations management, 25(2) (2007)

[10] He Yongyu. Analysis of the Causes of the Loss of Core Employees in Enterprises and Research on Countermeasures. Wuhan University (2005)

[11]Akakpo, Alfred, et al. Foresight, organization policies and management strategies in electric vehicle technology advances at Tesla. Futures Thinking and Organizational Policy. Palgrave Macmillan, Cham, 57-69 (2019).

[12] Meeks G, Meeks J G. The impact of M\&A on performance. Accounting for M\&A: Uses and Abuses of Accounting in Monitoring and Promoting Merger 208 (2020) 